\title{
The influence of microbial phytase supplementation to diets with high or low native phytase activity on sow reproductive traits and composition of colostrum and milk
}

\author{
E.R. Grela ${ }^{1,3}$, J. Matras ${ }^{1}$, A. Czech $^{2}$ and W. Krasucki ${ }^{1}$ \\ University of Life Sciences, \\ ${ }^{1}$ Institute of Animal Nutrition, \\ ${ }^{2}$ Department of Biochemistry and Toxicology \\ Akademicka 13, 0-934 Lublin, Poland
}

(Received 9 January 2009; revised version 4 June 2010; accepted 16 August 2010)

\begin{abstract}
The influence of intrinsic phytase and a microbial phytase additive on reproductive traits of sows, the composition of colostrum and milk, and on piglet rearing indices was studied. The two trials differed in the kind of grains used in the diets to give them lower (420-440 $\mathrm{PU} \mathrm{kg}^{-1}$, Trial 1) or higher (1000-1150 PU kg-1 , Trial 2) levels of intrinsic phytase. There were 3 feeding groups (34-35 animals in Trial 1 and 25 in Trial 2) in each experiment. In both trials, group 1 received the basic diet enriched with dicalcium phosphate, group 2, the basic diet without this additive (NC), and group 3 , the basic diet supplemented with $500 \mathrm{PU} \mathrm{kg}^{-1}$ microbial phytase. A higher number of liveborn piglets in group 3 in comparison with group 2 in Trial 2 was noted. Also, the body weight of piglets was significantly higher in groups 1 and 3 in comparison with the NC group. The microbial phytase supplement increased the concentration of $\mathrm{Zn}$ and $\mathrm{Cu}$ in colostrum and of $\mathrm{Zn}$ in sow milk, regardless of native phytase activity.
\end{abstract}

KEY WORDS: sows, piglets, phytase, colostrum, milk

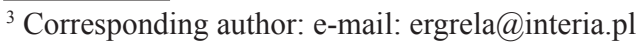




\section{INTRODUCTION}

Cereals, legumes, and other seeds used to formulate diets for pigs and other monogastric animals, contain poorly soluble calcium, magnesium and potassium salts of phytic acid, known as phytates, that bind a crucial part of the phosphorus in these feeds (Eeckhout and De Paepe, 1994). Although the seeds contain an abundant amount of phosphorus, this mineral contained in plants does not fulfill the requirement of growing single-stomached animals, as phytate phosphorus is poorly available in their digestive tract. This is because these animals do not produce adequate amounts of phytase which breaks down phytates. There can be two sources of phytase operating in the digestive tract of animals, intrinsic (native) phytase, occurring in plant feed, and phytase of microbial origin. The amount of native phytase differs tremendously between seeds of particular species, and varieties, and in only a few of them does it occur in high quantities. The latter include rye and triticale (Czech and Grela, 2004). Other feeds, e.g., maize and byproducts of the vegetable oil industry contain phytase in small quantities. Barley and wheat do not abound in this enzyme, either (Eeckhout and De Paepe, 1994).

Microbial phytase can be obtained biotechnologically and in recent years it has been introduced as an additive to plant feeds for pigs or poultry. Most of the experiments on utilizing microbial phytase have been performed on growing animals (Fandrejewski et al., 1999; Brady et al., 2002).

Knowledge about the effectiveness of microbial phytase as a dietary additive for sows is relatively limited. The results of some experiments have shown, however, analogically with trials on growing pigs, a beneficial effect of this enzyme on the digestibility of some nutrients and on the performance of these animals (Kemme et al., 1997; Jongbloed et al., 2004). It should be stressed that in almost all of the experiments on sows, the effect of phytase additive was examined when typical maize-soyabean meal diets, poor in intrinsic phytase, were fed (Hill et al., 2008). There are few studies concerning the effectiveness of microbial phytase in sow diets containing a high level of intrinsic phytase. Phytase activity (both intrinsic and microbial) contributes to the breakdown of phytates, increasing mineral and organic nutrient availability, and may improve the reproductive traits of sows and also modify colostrum and milk composition, especially mineral composition.

The purpose of the experiments was to examine the influence of microbial phytase supplementation to diets varying in native phytase content on sow reproduction parameters and on the contents of nutrients in colostrum and milk. 


\section{MATERIAL AND METHODS}

\section{Experimental diets}

The investigations comprised two nutritional trials, carried out on multiparous (Polish Landrace x Polish Large White) sows, 104 animals in Trial 1 (comprising 2 replicates, 60 sows in the first replicate and 44 sows in the second), and 75 in Trial 2 , in their $2^{\text {nd }}$ and $3^{\text {rd }}$ reproductive cycle. The trials differed in the kind of grains used in the diets. Trial 1 diets were based on feeds (barley, wheat, oats and rapeseed meal) containing a lower level of native phytase, whereas the Trial 2 mixtures (triticale, rye, oats and rapeseed meal) contained higher (over twice) intrinsic phytase. The sows' nutritional requirements were estimated according to NRC (1998) standards. The basic diets were prepared for both the pregnancy and lactation periods. Lactating diets were additionally supplemented with soyabean meal. There were 3 feeding groups containing 3435 or 24-25 animals in Trials 1 and 2, respectively. Group I (control) received the basic diets, enriched with dicalcium phosphate $\left(10 \mathrm{~g} \mathrm{~kg}^{-1}\right)$, group II (negative control), the basic diets without this additive, and group III, the basic diet (like group II), supplemented with microbial phytase (Natuphos ${ }^{\circledR}$, BASF, Germany - 500 PU $\cdot g^{-1}$ diet). During pregnancy the sows were kept in pens (4-5 animals each) and received $2.2 \mathrm{~kg}$ mixture until day 96 of pregnancy and then $3.5 \mathrm{~kg}$ until parturition. During lactation (individual cages), sows were fed their treatment diet, initially at $2.5 \mathrm{~kg}$, afterwards $1.5 \mathrm{~kg}$ of feed was cumulatively added each subsequent day until $3 \mathrm{~d}$ postpartum, when they were fed ad libitum until weaning $(28 \mathrm{~d})$. A more detailed description of the sow management was presented in an earlier paper (Czech and Grela, 2004).

\section{Animal management}

The number and body weight of newborns and the piglets on days 21 and 28 (weaning) of life were examined. The colostrum samples from 8 sows of each group were collected 4-8 $\mathrm{h}$ after farrowing and milk on the $7^{\text {th }}, 14^{\text {th }}$ and $21^{\text {st }}$ day of lactation. Colostrum and milk samples (50 to $60 \mathrm{~g}$ ), hand-milked from several teats (the right first thoracic gland) of a sow were collected after a single intramuscular injection of $2 \mathrm{IU}$ of oxytocin to induce milk let-down. The milk collected from each sow constituted a single sample. Milk was frozen immediately after collection and stored at $-5^{\circ} \mathrm{C}$. Then each sample was thawed, shaken, divided into three aliquots of 10 to $20 \mathrm{~g}$, and refrozen at $-20^{\circ} \mathrm{C}$ until the chemical analyses were performed. 


\section{Analytical procedures}

The contents of dry matter (DM), crude protein (CP - 976), ether extract (EE), ash, detergent fibre fraction (NDF and ADF - 973), $\mathrm{Ca}, \mathrm{P}, \mathrm{Na}, \mathrm{Cu}, \mathrm{Zn}, \mathrm{Fe}$ and Mn (968), in the diets were analysed according to AOAC (2000) methods; phytic phosphorus content, according to Oberleas (1971), and phytase activity, according to Engelen et al. (1994).

The contents of dry matter, protein, fat, lactose, ash, and minerals $(\mathrm{Ca}, \mathrm{P}, \mathrm{K}$, $\mathrm{Na}, \mathrm{Mg}, \mathrm{Fe}, \mathrm{Cu}, \mathrm{Zn}$ and $\mathrm{Mn}$ ) in colostrum and milk were estimated. Five $\mathrm{ml}$ of each composite colostrum and milk sample were pipetted into duplicate $50-\mathrm{ml}$ porcelain crucibles. The sample crucibles were placed in a drying oven at $105^{\circ} \mathrm{C}$ overnight. The dried crucibles were dry-ashed in a muffle furnace at $550^{\circ} \mathrm{C}$ for $24 \mathrm{~h}$. Ten $\mathrm{ml}$ of $6 \mathrm{~N} \mathrm{HCl}$ were added to each ashed crucible. The ashed samples were then solubilized in acid solution, transferred to $25-\mathrm{ml}$ volumetric flasks, and diluted to volume with double-deionized water. The molybdenum blue method was used to determine the phosphorus content, whereas zinc, manganese, copper, and iron were determined in the obtained mineralizates by flame atomic absorption spectrophotometry (FASA) using a UNICAM 939 spectrophotometer.

\section{Statistical analysis}

Experimental data were subjected to analysis of variance according to the following model for a randomized block design:

$$
\mathrm{Y}_{\mathrm{ijkl}}=\mu+\alpha_{\mathrm{i}}+\beta_{\mathrm{j}}+\chi_{\mathrm{k}}+(\alpha \beta)_{\mathrm{ij}}+(\alpha \chi)_{\mathrm{ik}}+(\beta \chi)_{\mathrm{jk}}+(\alpha \beta \chi)_{\mathrm{ijk}}+\mathrm{e}_{\mathrm{ijkl}}
$$

where: $Y_{\mathrm{ijk}}$ - independent variable, $\mu$ - overall mean, $\alpha_{\mathrm{i}}$ - effect of group (i=1, 2, $3), \beta_{j}$ - experimental effect - native and microbial phytase $(j=1,2), \chi_{k}$ - period in reproductive cycle $(\mathrm{k}=1,2)$, e - error contribution with an average and variance $\delta^{2}$.

\section{RESULTS}

Diet composition. The average content of crude protein in sow diets of Trial 1 amounted to about $144 \mathrm{~g}$ during pregnancy and $192 \mathrm{~g}$ in lactation, whereas in Trial 2, 139 and $194 \mathrm{~g} \mathrm{~kg}^{-1} \mathrm{DM}$, respectively (Table 1). The standard mixtures, both for pregnancy and lactation, contained about $6 \mathrm{~g}$ total phosphorus per $\mathrm{kg} \mathrm{DM}$. In the experimental treatments of both experiments, the level of this mineral was lower by about $30 \%$ (Table 1). Phytic phosphorus constituted $40-43 \%$ of total $\mathrm{P}$ in control group mixtures (pregnancy and lactation) and 58-63\% in the experimental 


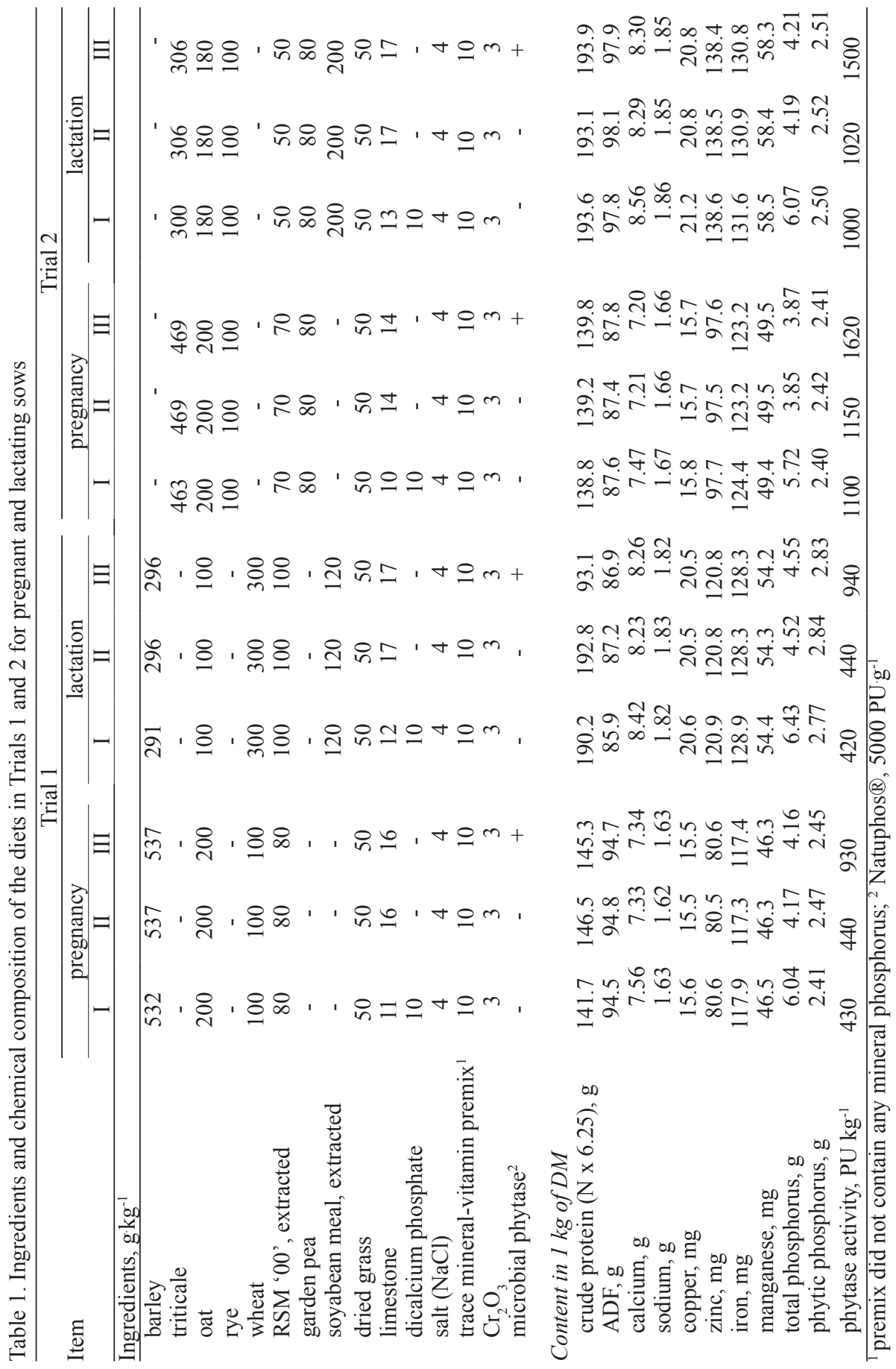


ones (without inorganic P supplementation).

The intrinsic phytase activity of Trial 1 diets amounted to about $430 \mathrm{PU}^{\mathrm{kg}} \mathrm{kg}^{-1}$, whereas in Trial 2 diets it was by about 700 and $600 \mathrm{PU}^{\mathrm{k} \mathrm{kg}^{-1}}$ higher in the pregnancy and lactation diets, respectively.

In the mixtures for group III (where total phytase activity was the sum of plant and microbial phytase), the activity of this enzyme ranged between 930 and $940 \mathrm{PU}^{\mathrm{kg}}{ }^{-1}$ in Trial 1, and 1500-1620 PU.kg ${ }^{-1}$ in Trial 2. The calcium content in the mixtures for experimental groups (II and III) was lower (by about 3\%) in comparison with the control, whereas the contents of the other minerals were similar.

Performance of piglets. Average daily feed intake by sows in pregnancy was about $2.5 \mathrm{~kg}$ (2.46 in Trial 1 and 2.42 in Trial 2) and oscillated around $7.0 \mathrm{~kg}$ during lactation in both trials. No differences between treatments were noted in this matter.

The piglets reared in Trial 2 (mixtures with the higher activity of native phytase) achieved somewhat higher performance indices (Table 2). Significant differences were reported in the body weight of piglets on days $21(\mathrm{P}=0.046)$ and $28(\mathrm{P}=0.044)$ of life. The dietary supplement of microbial phytase (group III) enabled obtaining similar or even somewhat better effects in piglet rearing than when calcium phosphate was used as an additive. A markedly higher number of liveborn and weaned piglets in group III was recorded in comparison with group II $(\mathrm{P} \leq 0.05)$ in both experiments. The lowest piglet losses up to day 28 of life were noted in group III of both experiments. Moreover, the litter weight at birth and on day 21 was higher $(\mathrm{P} \leq 0.05)$ in groups I (positive control) and III (phytase additive) compared with group II (negative control). Similarly, the body weight of individual piglets from groups I and III at birth, on days 21 and 28 of life, were also higher than in group II.

Colostrum and milk composition. The contents of basic nutrients in colostrum (Table 3) were not significantly dependent on the additive of fodder phosphate, activity of native phytase, or microbial phytase additive. Supplementing calcium phosphate or microbial phytase to the mixtures with low native phytase activity increased $(\mathrm{P} \leq 0.05)$ the phosphorus level in sow colostrum, whereas these additives did not cause statistically significant differences in the content of this mineral when the low native phytase diets were fed. Irrespective of native phytase activity in the diets, the microbial phytase supplement (500 PU. $\mathrm{kg}^{-1}$ ) elevated copper and zinc concentrations in sow colostrum.

Like in colostrum, no impact of native phytase activity or fodder phosphate and microbial phytase additives on the content of basic nutrients in milk was found (Table 4). The phosphorus content was significantly higher in the milk of sows 


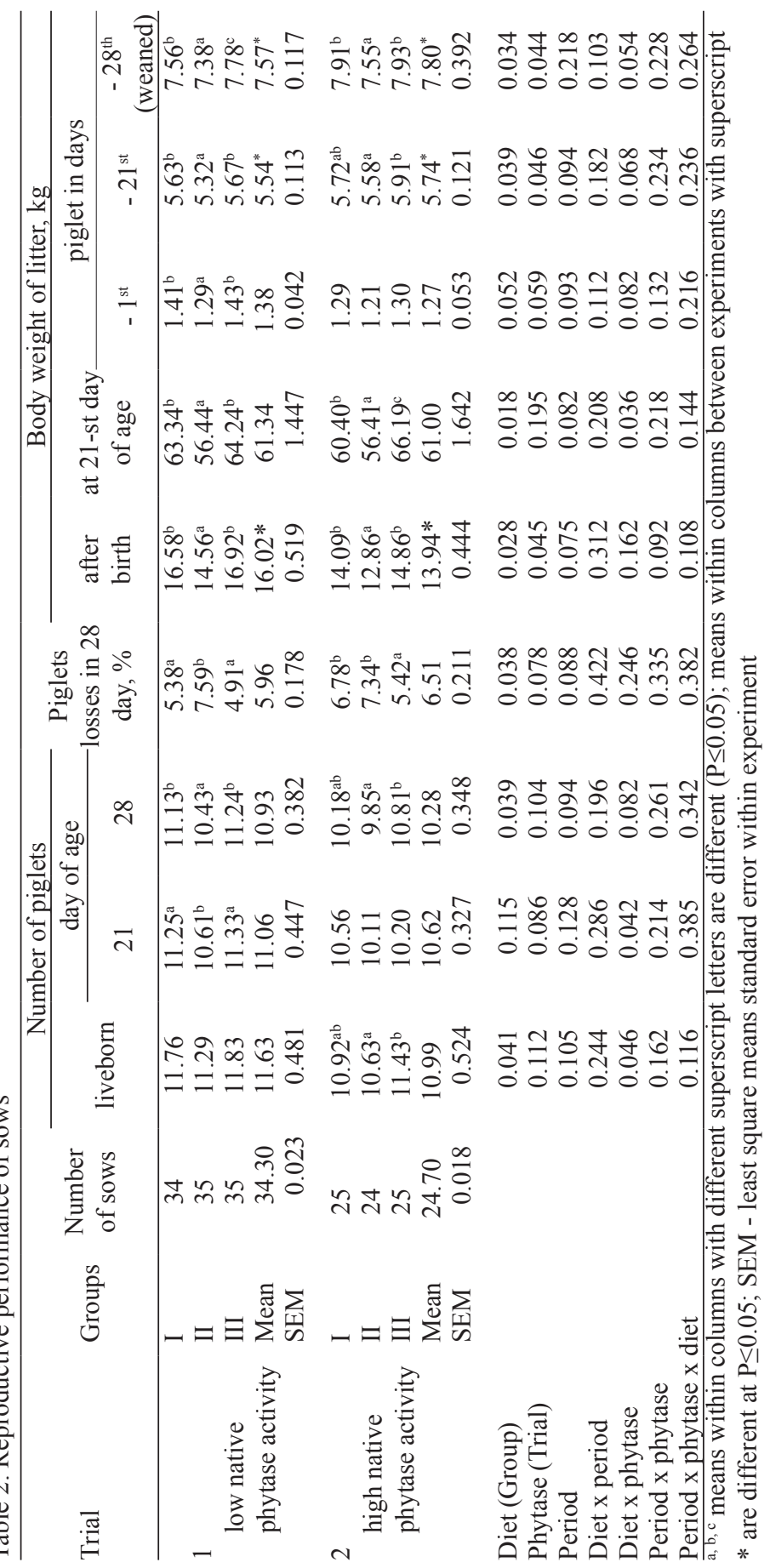




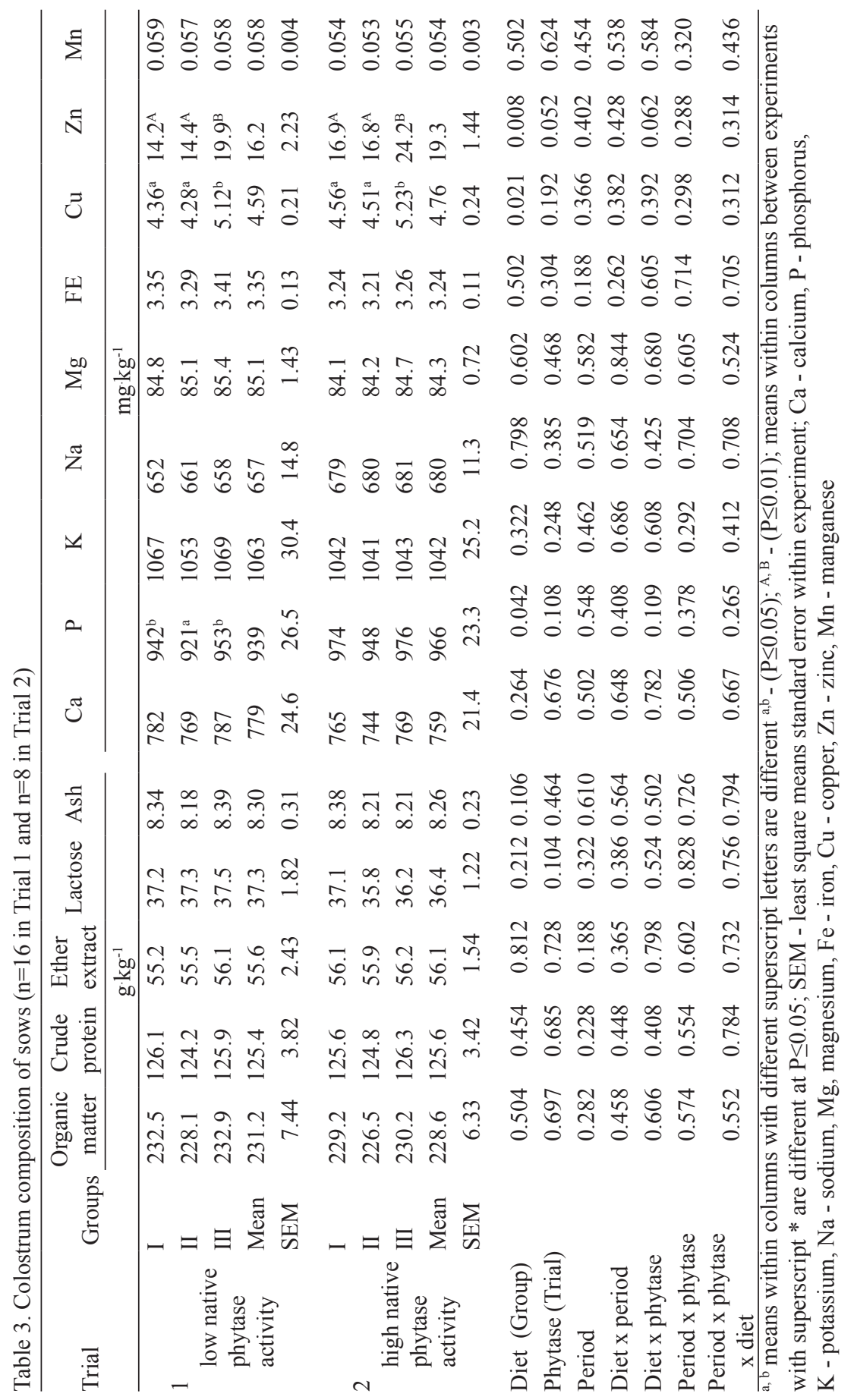




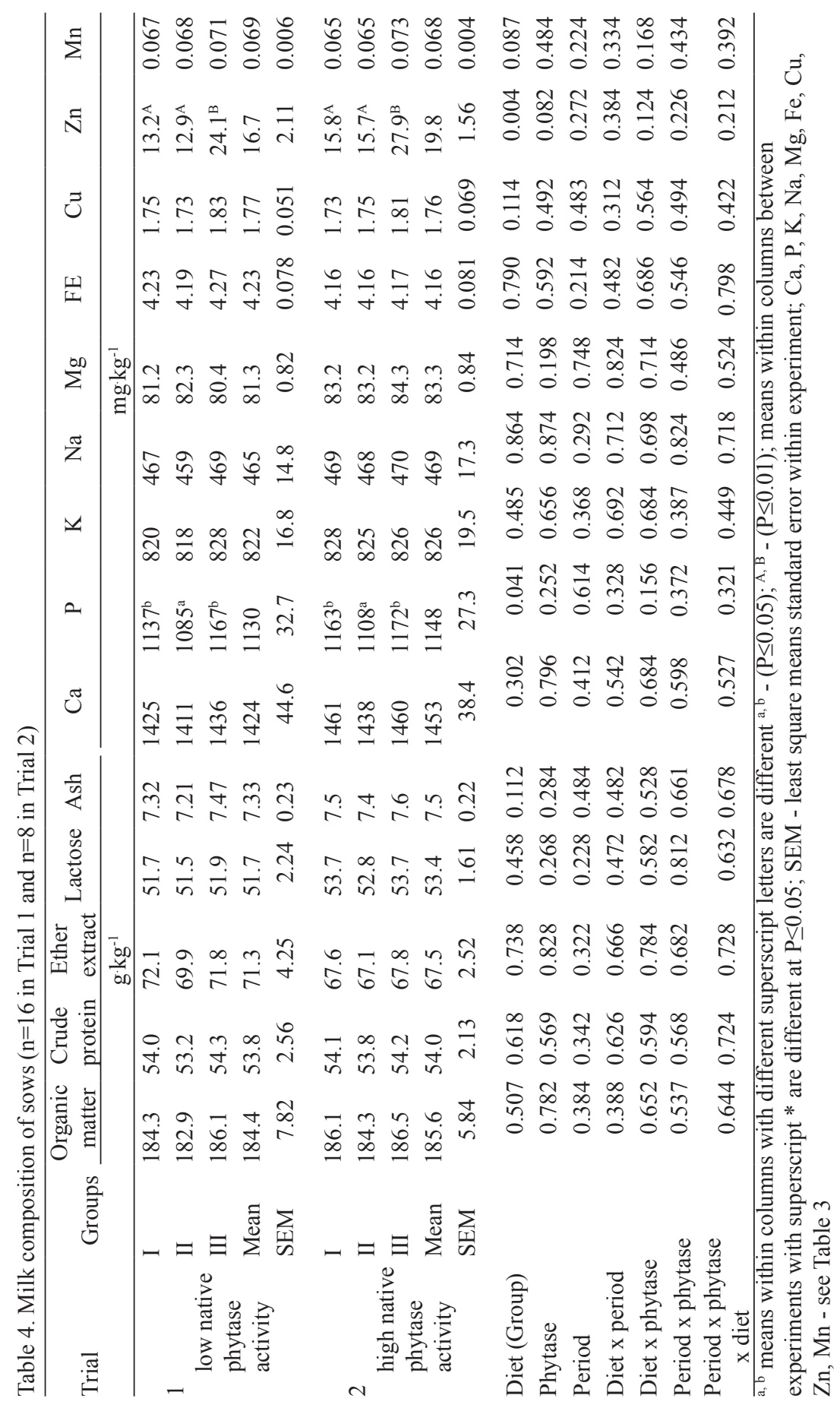


receiving phosphate or microbial phytase additive in their diets, irrespective of native phytase activity. The addition of microbial phytase significantly increased $(\mathrm{P} \leq 005)$ the zinc content in milk of group III sows, irrespective of the activity of native phytase. Also, a tendency towards elevated copper $(\mathrm{P}=0.114)$ and manganese $(\mathrm{P}=0.087)$ contents was found.

\section{DISCUSSION}

The conducted investigations revealed the role of native phytase as well as the usefulness of microbial phytase in sow nutrition during pregnancy and lactation. The results obtained in our trials confirm the opinions of some other authors that properly composed full-feed mixtures, containing either feeds with a high activity of native phytase or microbial phytase additive afford possibilities for better utilization of the minerals from plant feeds and for improved production effects. In the investigations conducted by Sands et al. (2001), the utilization of maize, which was characterized by higher availability of phosphorus (HAP), together with microbial phytase (600 PU kg-1) brought about the improvement of production effects as well as more efficient utilization of minerals in comparison with the traditional variety of maize (NML). It should be emphasized that phytase preparations, approved for use by competent authorities, are ecologically safe additives, not hazardous for gastrointestinal tract microflora. An excessive quantity of microbial phytase additive is not recommended only from the economical point of view. In the present investigations, piglets from the sows receiving the phytase preparation reached higher body weights on day 21 of life as well as at weaning. Similarly, beneficial productive effects of microbial phytase in sow nutrition were reported by Jongbloed et al. (2004), who examined the addition of microbial phytase to sow diets in the presence of formic acid. Dietary microbial phytase added to the mixtures without monocalcium phosphate appeared more effective in the diets with lower native phytase activity. This applies to the body weight lost at parturition and during lactation as well as net weight gains in the whole reproduction cycle. It should be mentioned that the influence of phytase on the availability of minerals, mainly phosphorus, is considerably lower in sows during pregnancy than lactation. This fact is probably associated with a higher content of nutritive fibre in the sow pregnancy diets resulting in the decreased availability of minerals. According to Jongbloed et al. (2004), sows utilize up to $0.77-0.83 \mathrm{~g} \mathrm{P} \cdot \mathrm{kg}^{-1}$ per day from the mixture (supplemented with 750 and 1000 PU.kg-1 microbial phytase) during lactation, whereas only 0.33-0.42 g

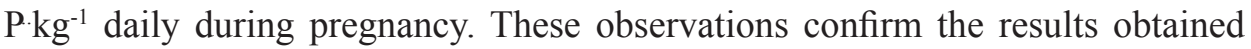
by Kemme et al. (1997). On the basis of the obtained results it can be inferred 
that each $10 \mathrm{~g} \mathrm{MCP}$ can be successfully replaced by the adding $500 \mathrm{PU}$ per $\mathrm{kg}$ of mixture. Similar results were noted in other investigations, indicating that microbial phytase decreases the negative influence of phytates as ANFs in pig nutrition by releasing some minerals (Czech and Grela, 2004; Liesegang et al., 2005) and other nutrients (Johnston et al., 2004).

The improvement of production effects of sows both in pregnancy as well as in lactation obtained in the present studies is the result of elevated digestibility and availability of some nutrients as well as phosphorus and calcium (unpublished). This fact is confirmed by the increased contents of some macro- and microminerals in sow blood immediately before weaning (Czech and Grela, 2004). The contents of organic nutrients and minerals in sow colostrum and milk depend on breed, successive lactation, lactation phase and on nutrition (Klobasa et al., 1987; Park et al., 1994; Csapó et al., 1996). Colostrum is characterized by an increased protein content, especially of the immunological fraction, whereas the fat content, quite low in colostrum, increases during lactation. The contents of organic nutrients obtained in this experiment both in colostrum and milk, confirm the results reported by Park et al. (1994) and Csapó et al. (1996). These parameters did not significantly depend on native phytase activity or the microbial phytase supplement. Supplementing microbial phytase to the diets without a fodder phosphate additive increasing the availability of phosphorus from phytates considerably elevated the concentration of this element in both colostrum and milk from sows fed the diets with low native phytase activity. This enzyme added to the diets rich in native phytase significantly increased the phosphorous content only in milk. Higher concentrations of zinc and copper in colostrum and zinc in the milk of sows supplied with the diets supplemented with microbial phytase preparation were also found, regardless of the native phytase activity. This corresponds with their elevated levels in the blood plasma of these animals (Czech and Grela, 2004).

\section{CONCLUSIONS}

Microbial phytase (Natuphos $\left.{ }^{\circledR}\right)$ added at a rate of about $500 \mathrm{PU} \cdot \mathrm{kg}^{-1}$ to pregnancy and lactation diets based on cereals (barley + oat + wheat) and rapeseed or soyabean meal resulted in higher daily gains of piglets. Synergistic effects of microbial phytase and native phytase on the reproductive performance of sows (number of liveborn piglets, their losses and growth during suckling up to 28 days) were noted.

The preparation containing microbial phytase increased the content of some minerals in colostrum and milk. 


\section{REFERENCES}

AOAC, 2000. Association of Official Analytical Chemists, Official Methods of Analysis. 14 Edition. Washington, DC

Brady S.M., Callan J.J., Cowan D., McGrane M., ODoherty J.V., 2002. Effect of phosphorus inclusion and calcium/phosphorus ratio on the performance and nutrient retention of growerfinisher pigs fed barley/wheat/soya bean meal-based diets. J. Sci. Food Agr. 82, 1780-1790

Csapó J., Martin T.G., Csapó-Kiss Z.S., Házas Z., 1996. Proteins, fats, vitamin and mineral concentrations in porcine colostrum and milk from parturition to 60 days. Int. Dairy J. 6, 881-902

Czech A., Grela E.R., 2004. Biochemical and haematological blood parameters of sows during pregnancy and lactation fed the diet with different source and activity of phytase. Anim. Feed Sci. Tech. 116, 211-223

Eeckhout W., De Paepe M., 1994. Total phosphorus, phytate-phosphorus and phytase activity in plant feedstuffs. Anim. Feed Sci. Tech. 47, 19-29

Engelen A.J., van der Heeft F.C., Randsdorp P.H.G., Smit E.L.C., 1994. Simple and rapid determination of phytase activity. J. AOAC Int. 77, 760-765

Fandrejewski H., Weremko D., Raj S., Skiba G., Han In K., 1999. Performance, body and carcass composition and bone characteristics of pigs fed rapeseed and soybean meal-cereal diets supplemented with microbial phytase. J. Anim. Feed Sci. 8, 533-547

Hill G.M., Link J.E., Rincker M.J., Kirkpatrick D.L., Gibson M.L., Karges K., 2008. Utilization of distillers dried grains with solubles and phytase in sow lactation diets to meet the phosphorus requirement of the sow and reduce fecal phosphorus concentration. J. Anim. Sci. 86, 112-118

Johnston S.L., Williams S.B., Southern L.L., Bidner T.D., Bunting L.D., Matthews J.O., Olcott B.M., 2004. Effect of phytase addition and dietary calcium and phosphorus levels on plasma metabolites and ileal and total-tract nutrient digestibility in pigs. J. Anim. Sci. 82, 705-714

Jongbloed A.W., van Diepen J.Th.M., Kemme P.A., Broz J., 2004. Efficacy of microbial phytase on mineral digestibility in diets for gestating and lactating sows. Livest. Prod. Sci. 91, 143-155

Kemme P.A., Jongbloed A.W., Mroz Z., Beynen A.C., 1997. The efficacy of Aspergillus niger phytase in rendering phytate phosphorus available for absorption in pigs is influenced by pig physiological status. J. Anim. Sci. 75, 2129-2138

Klobasa F., Werhahn E., Butler J.E., 1987. Composition of sow milk during lactation. J. Anim. Sci. $64,1458-1466$

Liesegang A., Loch L., Bürgi E., Risteli J., 2005. Influence of phytase added to a vegetarian diet on bone metabolism in pregnant and lactating sows. J. Anim. Physiol. Anim. Nutr. 89, 120-128

NRC, 1998. Nutrient Requirements of Swine. National Research Council. $10^{\text {th }}$ revised Edition. Washington DC

Oberleas D., 1971. The determination of phytate and inositol phosphates. In: D. Glick (Editor). Methods of Biochemical Analysis. Wiley and Sons, New York

Park Y.W., Kandeh M., Chin K.B., Pond W.G., Young L.D., 1994. Concentrations of inorganic elements in milk of sows selected for high and low serum cholesterol. J. Anim. Sci. 72, 13991402

Sands J.S., Ragland D., Baxter C., Joern B.C., Sauber T.E., Adeola O., 2001. Phosphorus bioavailability, growth performance, and nutrient balance in pigs fed high available phosphorus corn and phytase. J. Anim. Sci. 79, 2134-2142 